\title{
Study of Si-containing amorphous layer by electrical discharge coating
}

\author{
Nobuyuki SUMI*, Akihiro GOTO*, Hiroyuki TERAMOTO*, \\ Yusuke YASUNAGA*, Yoshikazu NAKANO** \\ (Received September 1, 2010)
}

\author{
* Mitsubishi Electric Corporation, 5-1-4, Yada-minami, Higashi-ku, Nagoya, Aichi, 461-8760, Japan \\ ** Mitsubishi Electric Corporation, 8-1-1, Tsukaguchi Honmachi, Amagasaki, Hyogo, 661-8661, Japan
}

\begin{abstract}
Electrical discharge machined surface using the silicon ( $\mathrm{Si}$ ) electrode has excellent corrosion resistance because of the formation of an amorphous layer. In this study, Si-containing amorphous layer which was comparatively thick (about $10 \mu \mathrm{m}$ ) was formed by electrical discharge coating, and the characteristics of this layer were investigated. Detailed metallographic analyses showed that the Si-containing amorphous layer had $7 \mathrm{wt} \%$ of $\mathrm{Si}$ and the fine structures with crystalline existed in this layer. From the water jet test, it became clear that the Si-containing amorphous layer had excellent erosion resistance in addition to excellent corrosion resistance. Furthermore, the Si-containing amorphous layer had comparatively low friction coefficient and high wear resistance. The heating test showed that the Si-containing amorphous layer was kept amorphous in 500 degrees or less and that when the heating temperature exceeded 600 degrees, the layer crystallized so that the microcrystals of $\mathrm{Fe}_{3} \mathrm{C}$ and $\alpha$-Fe were deposited.
\end{abstract}

Key words: electrical discharge coating, $\mathrm{Si}$, amorphous, corrosion resistance, erosion resistance

\section{INTRODUCTION}

Various surface treatments such as plating, Physical Vapor Deposition (PVD), Chemical Vapor Deposition (CVD), thermal spray or welding can provide wear resistance, corrosion resistance or high performance, etc. to parts or molds. These treatments have achieved great effects, but it is also true that there are many problems to be solved. For example, cleaning process is needed before PVD process, and CVD process causes thermal deformation. Welding needs experienced operators, and pre- and post-processes are necessary for it. The disposal of waste liquid is a problem for plating. Crack and peeling are the problems for every treatment, and equipment for these treatments is expensive.

On the other hand, the surface treatment using micro pulsed discharge is a new technology that can solve these problems. This technology is based on the electrical discharge machining technology. It is performed in a dielectric fluid using the electrode made of semi-sintered powder. The micro pulsed discharge is generated between the electrode and the workpiece, and melts the surface of the material of the electrode and the workpiece. The coating layer is formed by moving the melting electrode material to the melted workpiece surface. Since micro pulsed discharge repeated several thousand times a second is used, the heat is hardly concentrated. In addition, since the compositions of the coating layer and the workpiece are mixed at the interface, high adhesion between the layer and the workpiece is possible. Partial coating without pre-processing such as masking, and coating of inner surface of pipes are possible.

The idea to use the pulsed discharge for the surface treatment was reported in old documents of the Soviet Union. Then, Saito and Mohri found extremely excellent corrosion resistance with the formation of an amorphous layer on the surface of stainless steels to which electricity was discharged by using the silicon electrode, and this was a start of the electrical discharge coating research ${ }^{1)}$. Next, the electrode made of semi-sintered powder was developed and the movement and deposition of the electrode materials, such as copper, aluminum or tungsten carbide, to the surface of the workpiece were confirmed ${ }^{2)}$. Furthermore, it was possible to form hard titanium carbide coating layer which had high wear resistance when the electrode was made of the semi-sintered powder of titanium carbide. Therefore, this layer has been applied to molds in order to extend the lives.

On the other hand, the above-mentioned amorphous layer was not industrially used because the layer was thin (several micrometers) and the machining time was too long ${ }^{1)}$. Therefore, in this study, Si-containing amorphous layer which was comparatively thick (about $10 \mu \mathrm{m}$ ) was formed in a short time by optimized silicon electrode and coating conditions, and the characteristics of this layer were investigated in detail. In addition, since an amorphous substance is commonly known to crystallize at high temperature, the maximum temperature at which the layer can be kept amorphous was investigated. 


\section{EXPERIMENTAL METHODS AND CONDITIONS}

\subsection{Electrical Discharge Coating Method}

The schematic diagram of electrical discharge coating is shown in Figure 1 and the coating conditions are shown in Table 1. The electrode used in this study is a silicon electrode whose volume resistivity was $0.013 \Omega-\mathrm{cm}$. Workpieces are austenitic stainless steel SUS316, precipitation hardening stainless steel SUS630, and cold work tool steel SKD11. When the electrode wears $0.4 \mathrm{~mm}$ in length, the coating is completed. The coating time depends on the coating area. For instance, coating time is about 3 minutes per $100 \mathrm{~mm}^{2}$.

\subsection{Metallographic Observation Method}

The surface and cross-section of Si-containing amorphous layer are observed by Scanning Electron Microscope (SEM). Before the observation, the cross-section of the layer is ground by wet abrasive paper \#1000, finished up by buffing and etched by dip etching in aqua regia $\left(\mathrm{HCl}: \mathrm{HNO}_{3}=1: 3\right)$ for 35 seconds.

\subsection{Elemental Analysis Method}

Elemental mapping and point analysis of the cross-section of the layer are performed by Electron Probe Micro Analyzer (EPMA) to investigate the elemental distribution of the layer. Before the analyses, the cross-section of the layer is ground by wet abrasive paper \#1000, and finished up by buffing.

\subsection{Phase Identification Method}

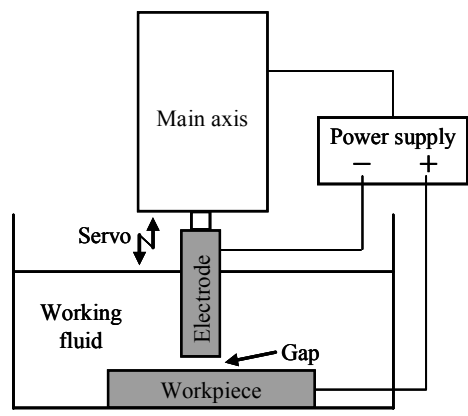

Fig.1 Schematic diagram

of electrical discharge coating

Table1 Condition of Electrical discharge coating

\begin{tabular}{c|c}
\hline Electrode & Si \\
Workpiece & SUS316,SUS630, \\
Open circuit voltage & $280 \mathrm{~V}$ \\
Discharge current & $8 \mathrm{~A}$ \\
Discharge duration & $8 \mu \mathrm{s}$ \\
Pulse interval & $32 \mu \mathrm{s}$ \\
Electrode wear & $0.4 \mathrm{~mm}$ \\
length & Electrode $(-)$ \\
Polarity & Workpiece $(+)$ \\
\hline
\end{tabular}

X-ray diffraction pattern of the surface of the Si-containing amorphous layer is measured by X-ray diffractometer (XRD) in order to identify phases of the layer. The characteristic X-ray is $\mathrm{Cu}-\mathrm{K} \alpha$, the tube voltage is $40 \mathrm{kV}$ and the tube current is $200 \mathrm{~mA}$.

In addition, the observation by Scanning Ion Microscope (SIM) and measurement of Electron Diffraction (ED) pattern by Transmission Electron Microscope (TEM) are performed to the cross-section of the layer. The samples for SIM observation and ED pattern measurement are made by Focused Ion Beam (FIB).

\subsection{Hardness and Roughness Measurement} Method

The hardness of the surface of the Si-containing amorphous layer is measured by Micro Vickers Hardness Tester using the load of $0.098 \mathrm{~N}$. Roughness of the surface of the layer is measured by the surface texture measuring instrument.

\subsection{Corrosion Resistance Evaluation Test Method}

Corrosion resistance of the Si-containing amorphous layer is evaluated by aqua regia dip test. Dip time is 1 hour. After dipping, the corrosion wastage is measured and the surface is observed by SEM. The workpiece is SUS316.

\subsection{Erosion Resistance Evaluation Test Method}

Erosion resistance of the Si-containing amorphous layer is evaluated by water jet test ${ }^{3)}$. Fig. 2 shows the schematic diagram of water jet test, and Table 2 shows the conditions of water jet test. After the test, the depth of the maximum damage is measured. The workpiece is SUS630.

\subsection{Friction and Wear Properties Evaluation Test Method}

Friction and wear properties of the Si-containing amorphous layer are evaluated by the ball-on-disk

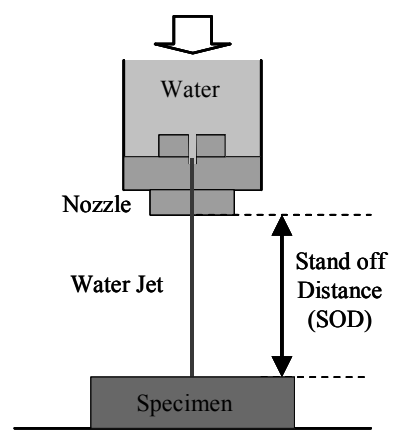

Fig.2 Schematic diagram of water jet test

Table2 Condition of water jet test

\begin{tabular}{c|c}
\hline Specimen & SUS630 with coating, \\
& SUS630, \\
Stellite No.6 \\
Nozzle diameter & $0.254 \mathrm{~mm}$ \\
Pressure & $100 \mathrm{MPa}$ \\
Stand off & $20 \mathrm{~mm}$ \\
Distance(SOD) & $5,10,20,60$, \\
Test time & $180,300,600 \mathrm{~s}$ \\
\hline
\end{tabular}




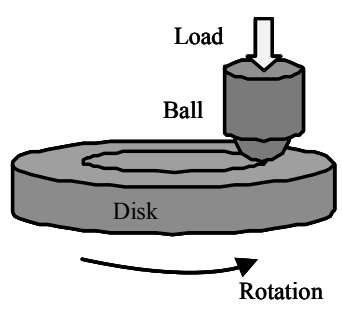

Fig.3 Schematic diagram of ball-on-disk test

Table 3 Condition of ball-on-disk test

\begin{tabular}{|c|c|c|}
\hline Ball & $\begin{array}{l}\text { Material } \\
\text { Diameter }\end{array}$ & $\begin{array}{c}\mathrm{Al}_{2} \mathrm{O}_{3} \\
6.35 \mathrm{~mm} \\
\end{array}$ \\
\hline \multirow[t]{2}{*}{ Disk } & Material & $\begin{array}{l}\text { SKD11 with } \\
\text { coating, } \\
\text { SKD11 }\end{array}$ \\
\hline & Diameter & $30 \mathrm{~mm}$ \\
\hline \multirow{3}{*}{ Test setting } & $\begin{array}{l}\text { Normal force } \\
\text { Revolution }\end{array}$ & $\begin{array}{c}1.0 \mathrm{~N} \\
191 \mathrm{rnm}\end{array}$ \\
\hline & $\begin{array}{l}\text { Rotation } \\
\text { diameter }\end{array}$ & $3.0 \mathrm{~mm}$ \\
\hline & Sliding distance & $141 \mathrm{~m}$ \\
\hline Environment & $\begin{array}{c}\text { Atmosphere } \\
\text { Lubricant }\end{array}$ & $\begin{array}{c}\text { Air } \\
\text { No lubricant }\end{array}$ \\
\hline
\end{tabular}

test. Fig.3 shows schematic diagram of the ball-on-disk test, and Table 3 shows the conditions of the test. After the test, the wear amount is measured.

\subsection{Heat Resistance Evaluation Test Method}

Heat resistance of the Si-containing amorphous layer is evaluated by the heating test. In this study, the heat resistance means the layer keeps amorphous. In order to clarify the maximum temperature at which the layer can be kept amorphous, the X-ray diffraction patterns, after the layer is maintained at each temperature in the atmosphere for 10 minutes and cooled in the furnace, are measured.

\section{RESULTS AND DISCUSSION}

\subsection{Metallographic Analysis Result}

SEM micrographs of the surface and cross-section of the Si-containing amorphous layer are shown in Figure 4. A lot of electrical discharge craters whose diameters are tens of micrometers are observed in the surface. The surface is very smooth, and neither crack nor void is observed. Thickness of the layer is approximately $10 \mu \mathrm{m}$ and it is uniformly formed.

Next, Figure 5 shows the elemental mapping of the cross-section of the layer. Silicon is concentrated in the dark gray part of Backscattered Electron Image (BEI) and the point analysis shows that the concentration of silicon is approximately $7 \mathrm{wt} \%$. A main element of the layer is iron. Moreover, the carbon that is presumed to be generated during the coating by resolving the fluid is also concentrated in

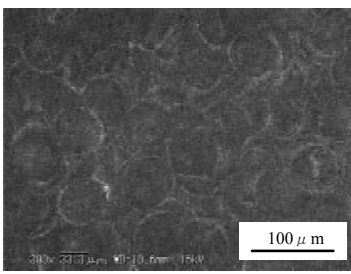

(a) Surface

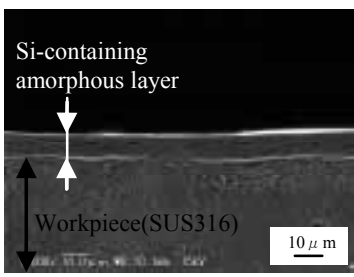

(b) Cross-section
Fig.4 SEM micrographs of the Si-containing amorphous layer

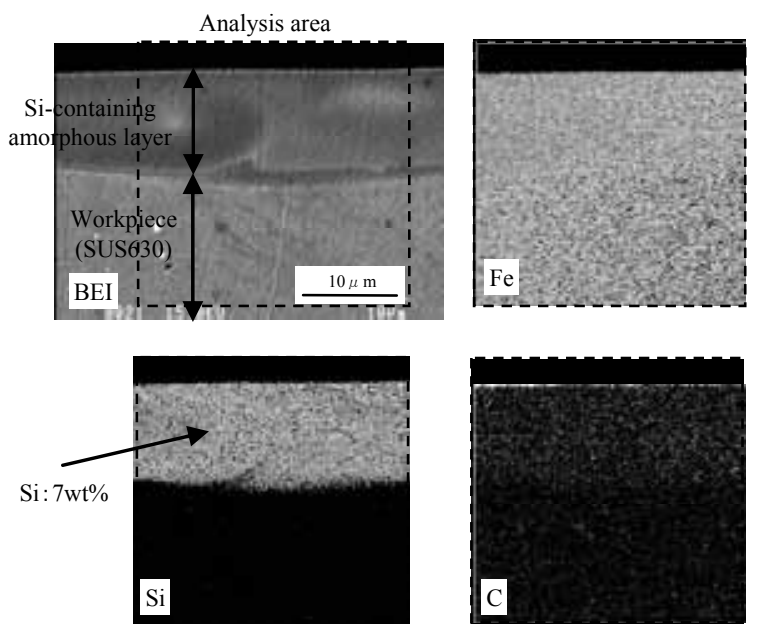

Fig.5 Element mapping in cross-section of the Si-containing amorphous layer

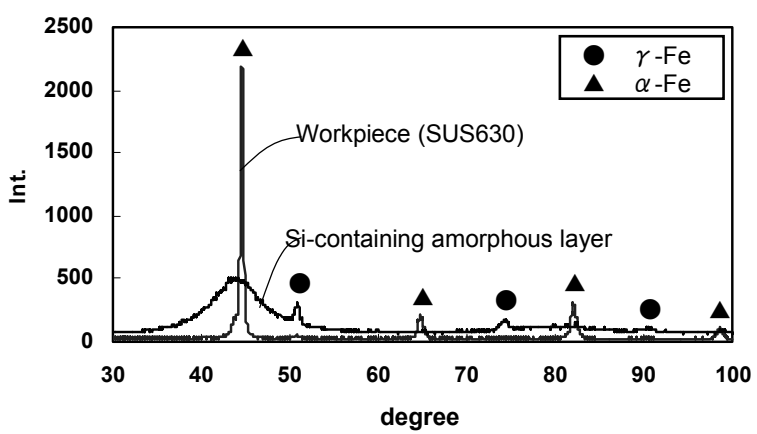

Fig.6 X-ray diffraction pattern of the Si-containing amorphous layer

the layer.

X-ray diffraction patterns of the Si-containing amorphous layer and workpiece are shown in Figure 6 . The pattern of the layer shows that the layer is amorphous because halo pattern is observed, and gamma iron $(\gamma-\mathrm{Fe})$ crystalline material exists in the layer because the diffraction peaks of $\gamma$-Fe crystal structure are observed. Meanwhile, the diffraction peaks of alpha iron $(\alpha-\mathrm{Fe})$ crystal structure are not observed. This shows that the surface of the 

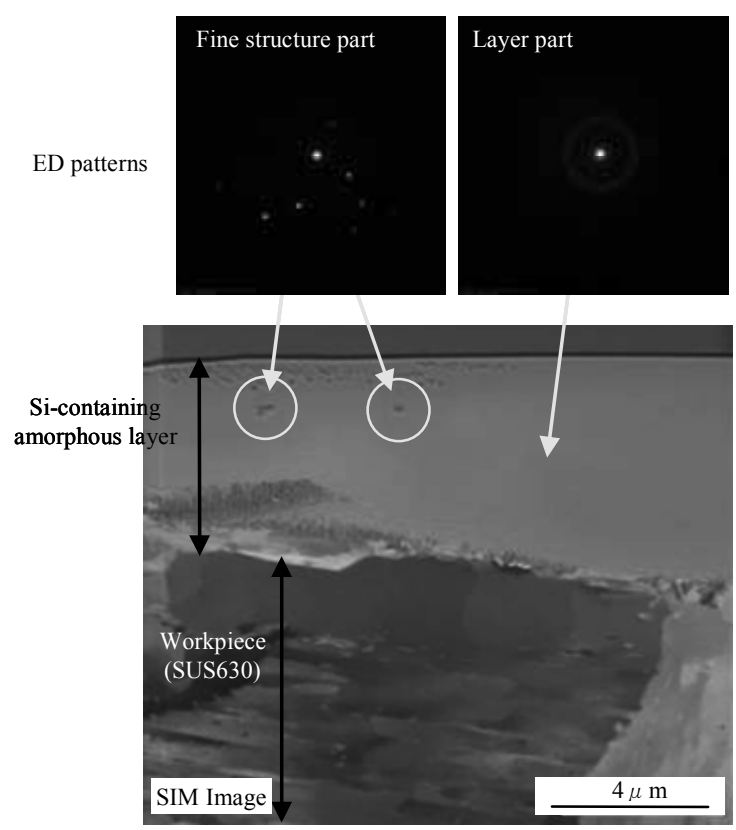

Fig.7 ED patterns and SIM micrograph of the Si-containing amorphous layer

workpiece is completely covered in the layer.

In addition, SIM micrograph of the cross-section of the layer and ED pattern of the layer are shown in Figure 7. From Figure 7, it can be seen that the layer is mainly amorphous and the fine structures (hundreds of nanometers) with crystalline existed in this layer. It is conceivable that these fine structures are the $\gamma$-Fe crystal structure from above-mentioned $\mathrm{X}$-ray diffraction result.

\subsection{Evaluation Results of Characteristics}

\subsubsection{Evaluation Result of Corrosion Resistance}

Figure 8 shows the result of the aqua regia dip test. After dipping, the area without Si-containing amorphous layer is corroded by $0.15 \mathrm{~mm}$. On the other hand, the area with the layer is not corroded at all. The SEM micrographs in Figure 8 show that the grain boundary is exposed in the area without the layer, while there is no damage in the area with the layer. The appearance during the test shows that a lot of bubbles are generated in the area without the layer as soon as dipping starts, while no bubble is generated in the area with the layer after the dipping starts. This result shows that the Si-containing amorphous layer has high corrosion resistance.

From Figure 8, it can be seen that the grain boundary is exposed in the area without the layer. This shows that the corrosion of the area without the layer progresses from the grain boundary. Meanwhile, it is conceivable that the layer has high corrosion resistance because there is no grain boundary in the layer so that the grain boundary corrosion doesn't occur.
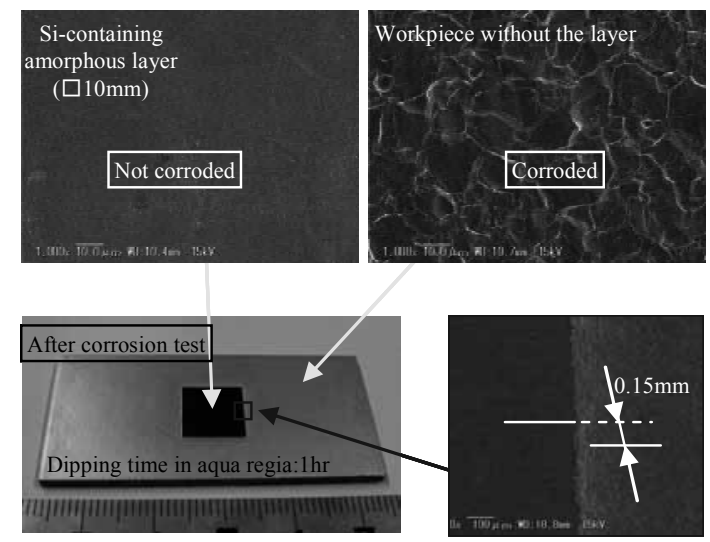

Fig. 8 Result of the aqua regia dip test of the Si-containing amorphous layer
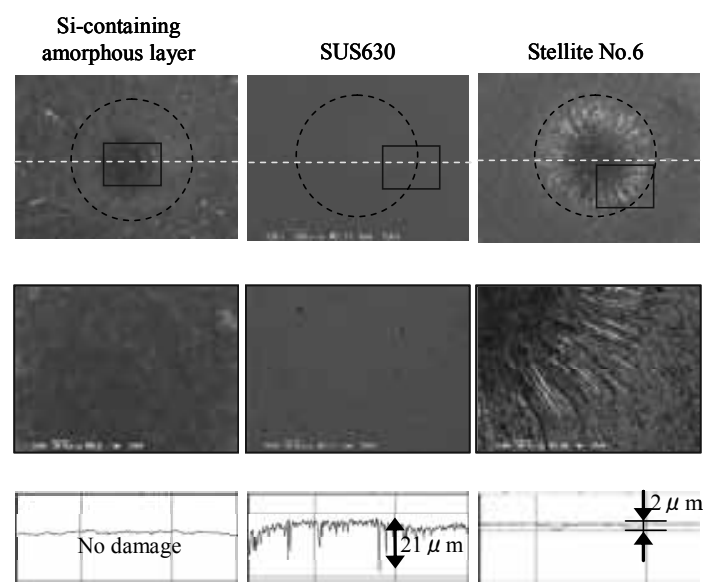

Fig.9 SEM micrographs and maximum damage depth of the Si-containing amorphous layer after water jet test for 300 seconds

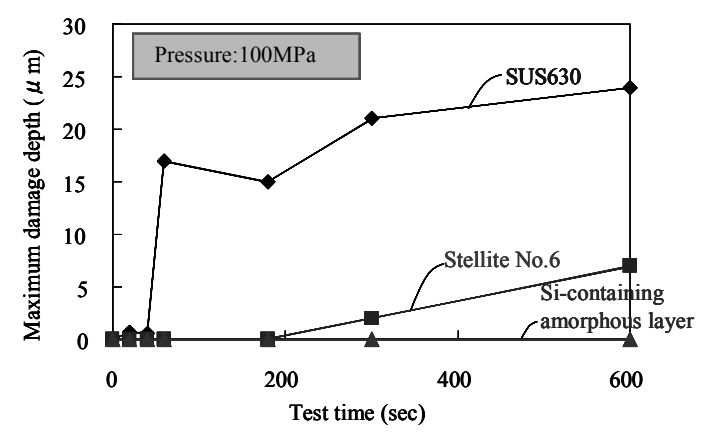

Fig.10 Relationship between the water jet test time and the maximum damage depth

\subsubsection{Evaluation Result of Erosion Resistance}

Figure 9 shows the SEM micrographs and the maximum damage depth of the Si-containing 
amorphous layer after the water jet test for 300 seconds. Co-alloy (Stellite No.6) which is usually used to prevent erosion and the workpiece (SUS630) without the layer are also tested. Roughness and hardness of these test pieces before the test are as follows. Si-containing amorphous layer: $1.4 \mu \mathrm{mRz}$, 850HV, SUS630: $0.3 \mu \mathrm{mRz}, 380 \mathrm{HV}$, Stellite No.6: $0.2 \mu \mathrm{mRz}, 490 \mathrm{HV}$.

As can be seen from Figure 9, SUS630 is locally damaged by about tens of micrometers in depth, and Stellite No.6 is circularly damaged by about several micrometers in depth though it is shallower than SUS630. On the other hand, Si-containing amorphous layer is not damaged in the direction of depth at all.

Next, Figure 10 shows the relationship between the test time and the maximum damage depth. In SUS630, damage starts 60 seconds after the test starts. In Stellite No.6, damage starts 300 seconds after the test starts. The maximum damage depth becomes deeper as the test time becomes longer. On the other hand, there is no damage in the Si-containing amorphous layer at all.

Therefore, it becomes clear that this Si-containing amorphous layer has high erosion resistance. It is conceivable that this is because the grain boundary fracture does not occur in the Si-containing amorphous layer and the layer is comparatively hard and smooth.

\subsubsection{Evaluation Result of Friction and Wear Properties}

Figure 11(a) shows the measurement result of friction coefficient of the Si-amorphous layer and SKD11 without the layer. Roughness and hardness of these test pieces before the test are as follows. Si-containing amorphous layer: $2.5 \mu \mathrm{mRz}, 900 \mathrm{HV}$, SKD11: $0.07 \mu \mathrm{mRz}, 700 \mathrm{HV}$. As can be seen from Figure 11(a), the friction coefficient of the layer is approximately 0.35 , while the friction coefficient of SKD11 is approximately 0.8 . Next, the ratio of wear is shown in Figure 11(b). The ratio of the wear amounts of the layer is about 0.38 of SKD11 without the layer.

Therefore, it is found that the friction coefficient of the Si-containing amorphous layer is comparatively low and the wear resistance of the layer is higher than SKD11 without the layer. Although the reason why there are high wear resistance and low frictional properties in the layer has not yet been clarified, it is conceivable that this is because the layer is amorphous and is comparatively hard and smooth.

\subsubsection{Evaluation Result of Heat Resistance}

Figure 12 shows the result of heating test of the Si-containing amorphous layer. When the heating temperature is 500 degrees or less, the halo pattern and the diffraction peaks of $\gamma$-Fe are observed as in the case of non-heating.

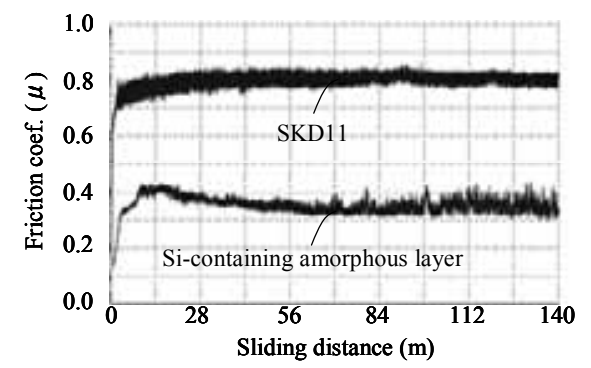

(a) Friction coefficient

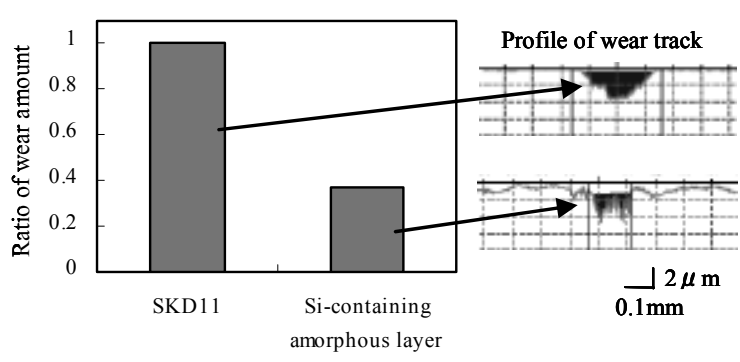

(b) Ratio of wear amount

Fig. 11 Result of the ball-on-disk test of the Si-containing amorphous layer

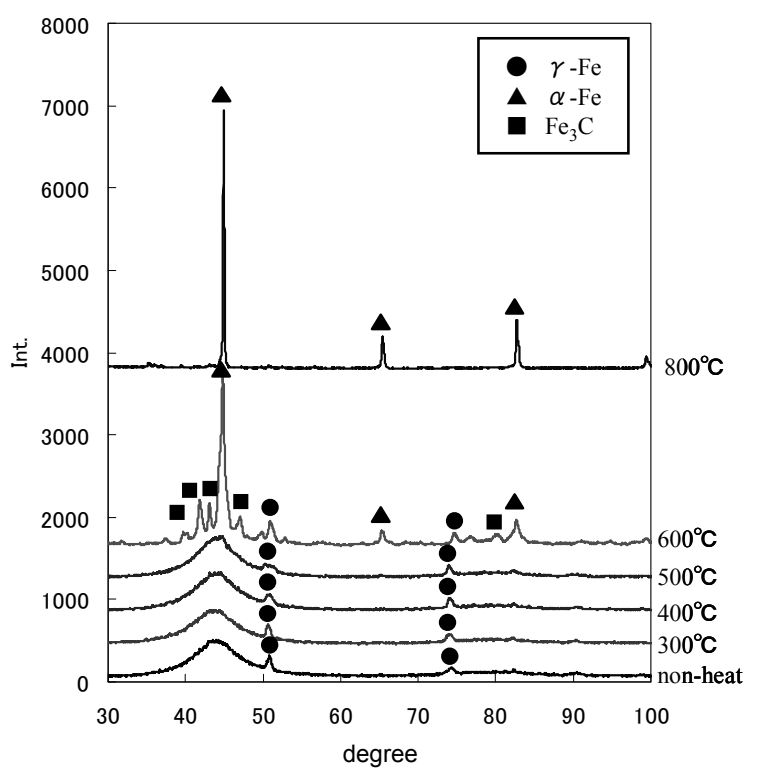

Fig.12 Result of the heating test of the Si-containing amorphous layer

Meanwhile, when the heating temperature exceeds 600 degrees, the diffraction peaks of cementite $\left(\mathrm{Fe}_{3} \mathrm{C}\right)$ are observed and the diffraction intensity of $\alpha$-Fe become higher and the diffraction peaks of $\alpha$-Fe become sharper. This result shows that the layer can be kept amorphous in 500 degrees or 
less and that when the heating temperature exceeded 600 degrees, the layer crystallizes so that the microcrystals of $\mathrm{Fe}_{3} \mathrm{C}$ and $\alpha$-Fe are deposited.

In addition, when the heating temperature exceeds 800 degree, the diffraction peaks of $\mathrm{Fe}_{3} \mathrm{C}$ and $\gamma-\mathrm{Fe}$ are not observed and only the diffraction peaks of $\alpha$-Fe are observed.

Next, the hardness of the layer after heating test is as follows. When the heating temperature is 500 degrees or less, the hardness of the layer is approximately $850 \mathrm{HV}$. When the heating temperature exceeds 600 degrees, the hardness of the layer is approximately $1300 \mathrm{HV}$. In addition, when the heating temperature exceeds 800 degrees, the hardness of the layer is approximately $850 \mathrm{HV}$.

Therefore, it becomes clear that the layer becomes harder when the heating temperature exceeds 600 degrees because the microcrystals of $\mathrm{Fe}_{3} \mathrm{C}$ and $\alpha-\mathrm{Fe}$ are distributed in the layer.

\section{CONCLUSIONS}

In this paper, Si-containing amorphous layer was formed by electrical discharge coating, and the characteristics of this layer were investigated.

The following conclusions were obtained.

(1) Si-containing amorphous layer which is comparatively thick (about $10 \mu \mathrm{m}$ ) is formed in a short time by optimized silicon electrode and coating conditions.

(2) Elements of silicon and carbon are concentrated in the Si-containing amorphous layer and the concentration of silicon is approximately 7 wt $\%$. It is conceivable that the $\gamma$-Fe crystal fine structures exist in the layer.

(3) The Si-containing amorphous layer has excellent corrosion resistance in addition to excellent erosion resistance.

(4) The friction coefficient of the Si-containing amorphous layer is comparatively low (approximately 0.35) and the wear resistance of the layer is higher than SKD11 without the layer.

(5) The layer can be kept amorphous in 500 degrees or less, and when the heating temperature exceeded 600 degrees, the layer crystallizes so that the microcrystals of $\mathrm{Fe}_{3} \mathrm{C}$ and $\alpha$-Fe are deposited.

\section{REFERENCES}

1) SUZUKI Masahiko, MOHRI Naotake, SAITO Nagao : Surface Modification by Means of the Electrical Discharge Machining, J. Jpn. Soc. Precis. Eng., Vol.53,No.2(1987)PP.243-248(in Japanese). 2) MOHRI Naotake , SAITO Nagao , TSUNEKAWA Yoshiki, MOMIYAMA Hidenori, MIYAGAWA Akihiko : Surface Modification by Electrical Discharge Machining : Composite Electrode Method, J. Jpn. Soc. Precis. Eng., Vol.59,No.4(1993)PP.625-630(in Japanese).

3) MIYATA Hirokazu, ISOMOTO Yoshinori : Erosion Phenomenon Caused by Water Droplet Impingement and Life Prediction of Industrial Materials: Part 1-Investigation of Droplet Impingement Factors and Erosion Testing Methods, Zairyo-to-kankyo,57,(2008)138-145 (in Japanese) 